\title{
Feedbacks between multiple nutrient cycles facilitated the expansion of eukaryotic life at ca. $1.56 \mathrm{Ga}$
}

XINQIANG WANG ${ }^{12 *}$, ZHIPENG WANG ${ }^{1}$, XIAOYING $\mathrm{SHI}^{12 *}$, DONGJIE TANG ${ }^{3}$, EVA E. STÜEKEN ${ }^{4}$, HuYUE SONG ${ }^{5}$, YONGBO PENG ${ }^{26}$

${ }^{1}$ School of Earth Sciences and Resources, China University of Geosciences (Beijing), Beijing 100083, Chin

${ }^{2}$ Department of Geology \& Geophysics, Louisiana State University, Baton Rouge, LA 70803, USA

${ }^{3}$ Institute of Earth Sciences, China University of Geosciences (Beijing), Beijing 100083, China

${ }^{4}$ School of Earth and Environmental Sciences, University of St Andrews, St Andrews KY16 9AL, Scotland, UK

${ }^{5}$ State Key Laboratory of Biogeology and Environmental Geology, China University of Geosciences, Wuhan 430074, China

${ }^{6}$ School of Earth Sciences and Engineering, Nanjing University, 210023 Nanjing, China

Recent studies have revealed a significant ocean oxygenation episode and an evolutionary leap of eukaryotes at early Mesoproterozoic. However, the potential role of nitrogen availability in these environmental and biological events has not been investigated. Here we present an integrated study of nitrogen isotopes $\left(\delta^{15} \mathrm{~N}\right)$, organic carbon isotopes $\left(\delta^{13} \mathrm{C}_{\mathrm{org}}\right)$, and major and trace element concentrations from the Member III of the Gaoyuzhuang Formation in the central North China Craton where the earliest macroscopic multicellular eukaryotic fossils were reported. The enrichments of redox-sensitive elements (Mo, U, V), coupled with Mo-U covariations, $\delta^{13} \mathrm{C}_{\text {org }}$ and $\mathrm{I} /(\mathrm{Ca}+\mathrm{Mg})$, indicate that the Gaoyuzhuang Member III in the study area was deposited in largely suboxic-anoxic environments with ephemeral occurrences of euxinia. These data reinforce previous inferences of a strongly redox stratified ocean during the early Mesoproterozoic, but pulse of oxygenation event may result in the deepening of chemocline. The persistently high $\delta^{15} \mathrm{~N}$ values from the study section likely reflect aerobic $\mathrm{N}$ cycling and the presence of a fairly stable nitrate pool in the surface oxic layer, possibly due to the combined effects of oxygenation and low primary production. Availability of nitrate may have contributed to the expansion of eukaryotic life at this time but it was not the only trigger. Instead, this evolutionary leap was likely facilitated by multiple environmental factors, including a rise in $\mathrm{O}_{2}$ levels and increasing supplies of phosphorus and other bio-essential trace elements.

Corresponding author: X Wang (wxqiang307@126.com) 